Cotterill, J. A. (1996) Body dysmorphic disorder. Dermatology Clinics, 14, 457-463.

Phillips, K. A. (200I) Body dysmorphic disorder. In Somatoform and Factitious Disorders (ed. K. A. Phillips), pp. 67-94. Washington, DC: American Psychiatric Press.

\& Castle, D. J. (200I) Body dysmorphic disorder. Disorders of Body Image (eds D. J. Castle \& K. A. Phillips). Petersfield: Wrightson Biomedical, in press.

Veale, D., Boocock, A., Gournay, K., et al (1996) Body dysmorphic disorder. A survey of fifty cases. British Journal of Psychiatry, 169, 196-201.

K. A. Phillips Butler Hospital, Brown University School of Medicine, Providence, Rhode Island, USA

D. J. Castle Fremantle Hospital, University of Western Australia, PO Box 480, Fremantle, WA 6959, Australia

\section{Advice for authors is premature}

In their recent article Patel \& Sumathipala (2001) lament the low level of international representation in high-impact psychiatry journals and argue that such a phenomenon is curtailing the development of the psychiatric discipline in both developed and developing countries. Although I agree with the basic argument put forward, some of the advice given to prospective authors is, at best, premature. To be more specific, they explicitly advise authors from countries outside the 'Euro-American' group (Western Europe, North America and Australia/New Zealand) to submit their manuscripts to the three high-impact European psychiatric journals (British Journal of Psychiatry, Acta Psychiatrica Scandinavica and Psychological Medicine), rather than to the three high-impact American psychiatric journals (American Journal of Psychiatry, Archives of General Psychiatry and Schizophrenia Bulletin), because the former publish a higher proportion of articles from 'rest-of-the-world' (RoW) authors. While this may be so, and indeed their data suggest that it is, it does not necessarily follow that such authors will improve their chances of publication by submitting to the three European journals in preference to the three American ones. Such authors should be concerned with differential acceptance rates rather than with the proportion of published papers by RoW authors. Although no acceptance rate data were provided by the three American journals, data on the three European journals indicated a much lower acceptance rate for RoW authors than for Euro-American ones (the fact that the three American journals refused to provide acceptance rate data should not be assumed to indicate that they show an even greater bias). Given these data, it would seem wrong to suggest that RoW authors should favour the three European journals when submitting manuscripts for publication. Such advice should perhaps be reserved until the data are more conclusive.

Patel, V. \& Sumathipala, A. (200I) International representation in psychiatric literature. Survey of six leading journals. British Journal of Psychiatry, 178 406-409.

G. J. Faunce Department of Psychiatry, University of Sydney, NSW 2006, Australia

\section{Chromosome 22qll deletions and severe learning disability}

In a previous study (Murphy et al, 1998) we identified 74 patients thought to be at risk of velo-cardio-facial syndrome (VCFS) from 265 hospitalised individuals with learning disability. We screened these 74 people and found two cases of VCFS, giving a minimum prevalence of $0.7 \%$ in the entire sample. Recently, we found a further individual with VCFS among the 191 individuals who were not selected for screening. This gives a revised minimum prevalence estimate of $1.1 \%$.

The patient, a 50-year-old Caucasian female with severe learning disabilities, had no reported complications arising during gestation, delivery or early childhood. Developmental milestones were globally delayed. She presented to the psychiatric services as a teenager with a 12-month history of becoming withdrawn and subdued, having lost some previously learned skills and displaying outbursts of bizarre behaviour and aggression. She was subsequently admitted on several occasions and was definitively admitted as a longterm patient within 2 years of initial presentation, owing to her enduring challenging behaviour. At this time, her mental age was assessed to be between 2 and 4 years and she had not developed any effective speech or signing. She remained in hospital for over 30 years, then was discharged to a staffed house in the community. While in hospital she remained largely quiet, timid and withdrawn. However, there were episodes of prolonged challenging behaviour, during which time she became suspicious, would scream, cry and make unintelligible noises, often accompanied by physical aggression. These episodes were treated with a variety of behavioural modification strategies, augmented with various antipsychotic preparations with partial success. No formal diagnosis of psychotic illness was made and she was therefore not selected for chromosome 22q11 deletion studies as she did not meet screening criteria (Murphy et al, 1998).

In 1999 she was readmitted to the local assessment and treatment unit because of aggression, agitation, deterioration in her skills and bizarre behaviour including ambitendence, vocalising and gesturing as if responding to abnormal perceptions. It was felt that these symptoms were suggestive of a psychotic disorder and she was successfully treated with an atypical antipsychotic. A provisional diagnosis of schizophrenia was made, although one cannot be categorical in individuals lacking effective communication skills (Royal College of Psychiatrists, 2001). Fluorescence in situ hybridisation (FISH) analysis confirmed a deletion or chromosome 22q11.

In our 1998 study, we concluded that chromosome 22q11 deletions appear to be aetiologically significant in a proportion of individuals with idiopathic learning disability, especially in those with mild learning disability and psychosis. The importance of the patient described above is that she has severe rather than mild learning disability and that, despite presenting with seriously challenging behaviour at the time of the study, she was not diagnosed as having a formal psychotic illness.

Although individuals with VCFS are characterised predominantly by borderline or mild learning disability, it is important for clinicians to be aware that occasionally such individuals may present with more severe learning disabilities, as in this case. We suggest that any individual with moderate or severe learning disabilities with a history of bizarre or uncharacteristic challenging behaviour, even in the absence of a formal diagnosis of psychosis, should be referred for chromosome 22q11 deletion studies.

Murphy, K. C., Jones, R. G., Griffiths, E., et al (1998) Chromosome 22qll deletions. An under-recognised cause of idiopathic learning disability. British Journal of Psychiatry, 172, 180-183.

Royal College of Psychiatrists (200I) DC-LD Diagnostic Criteria for Psychiatric Disorders for use with Adults with Learning Disabilities/Mental Retardation (Occasional Paper OP48). London: Gaskell.

R. G. Jones, J. Morley-Canellas Learning Disability Directorate, Bro Morgannwg NHS Trust, Treseder Way, Caerau, Cardiff CF5 5WF, UK 
M. J. Owen Department of Psychological Medicine, University of Wales College of Medicine, Heath Park, Cardiff CFI4 4XM, UK

K. C. Murphy Institute of Psychiatry, De

Crespigny Park, Denmark Hill, London SE5 8AF, UK

\section{Earliest evidence of post-traumatic stress?}

Written evidence of stress reactions to trauma is relatively new, dating back to the 17th century (Trimble, 1985). I would like to present the oldest post-traumatic reaction in recorded history. This historical evidence is based on a cuneiform tablet describing the death in battle of King Urnamma (2111-2094 BC) and its consequences (Fluckiger-Hawker, 1999). This tablet provides the earliest known description of exposure to a traumatic event leading to a post-traumatic reaction. The following paragraphs present the destruction bestowed on Sumer and the people's reaction to the event:

"From the $[\ldots$, the ...] was $[. .$.$] evenly in/on$ the land.

[The ...] struck, the palace(s) was collapsed.

[The ... .] spread panic rapidly among its Blackheaded who dwelt there.

[The...] established its abandoned places in Sumer.

In its vast [...] cities are destroyed, the people are seized with panic.

Evil came upon Ur....".

(Urnamma A: I-6. In Fluckiger-Hawker,

1999)

"They weep bitter tears in their broad squares where merriment had reigned.

With their bliss (fullness) having come to an end the people do not sleep soundly".

(Urnamma A: 19-20. In Fluckiger-Hawker,

These verses describe exposure to a traumatic event, followed by psychiatric symptoms. This evidence gives us a glimpse of a traumatic reaction in antiquity and allows us to compare it to modern reactions. Furthermore, it reveals the core features of post-traumatic stress disorder, which are based on exposure to a traumatic event followed by characteristic symptoms such as sleep disturbances (American Psychiatric Association, 1994).

American Psychiatric Association (1994) Diagnostic and Statistical Manual of Mental Disorders (4th edn) (DSM-IV). Washington, DC: APA.

Fluckiger-Hawker, E. (1999) Urnamma of Ur in Sumerian Literary Tradition. Guttingen: University Press Fribourg.

Trimble, M. R. (1985) Post-traumatic stress disorder history of a concept. In Trauma and its Wake: The Study and Treatment of Post-traumatic Stress Disorder (ed. C. R. Figley), pp. 5-14. New York: Brunner/Mazel.

M. Ben Ezra Department of Psychology, Tel Aviv University, Tel Aviv 69978, Israel

\section{One hundred years ago}

\section{Isolating the phthisical insane}

THE Journal of Mental Science (January, 1900) publishes a paper on the necessity of isolating the phthisical insane read at a recent meeting of the Medico-Psychological Association by Dr. Eric France of Claybury Asylum. The paper shows from the postmortem records of the London County Asylums at Claybury, Colney Hatch, and Cane Hill that while 67 deaths were certified as due to tubercle, active tubercle was found post mortem in 112 cases, this last figure not including 10 doubtful cases. "It will thus be seen," he says, "that at these three asylums the number of patients dying with active tubercle, as compared with those certified as dying from this cause, practically stand in the proportion of two to one." A number of valuable tables of mortality follow and the conclusion urged is that cases of phthisis in asylums should be isolated in the early stage of the disease before they begin to disseminate the bacillus to the detriment of others. The tuberculin test is now generally admitted to be the most valuable diagnostic measure for indications of early mischief. Of 55 suspected cases injected with tuberculin 45 reacted and 10 did not react. Of the latter five were alive and healthy in July, 1899, the other five died and the post-mortem examinations made disclosed no trace of tubercle. In the discussion which followed the paper Sir William Broadbent, Sir James Crichton Browne, and Professor Clifford Allbutt strongly urged the needs of special provision for the isolation and open-air treatment of such cases.

\section{REFERENCE}

Lancet, 27 January 1900, 248.

Researched by Henry Rollin, Emeritus Consultant Psychiatrist, Horton Hospital, Epsom, Surrey 